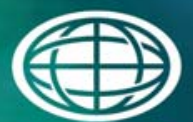

Savannah River

National Laboratory "m

OPERATED BY SAVANNAH RIVER NUCLEAR SOLUTIONS

\title{
CRADA Final Report for CRADA No. CR-12-006
}

Operation and Testing of an $\mathrm{SO}_{2}$-depolarized Electrolyzer (SDE) for the Purpose of Hydrogen and Sulfuric Acid Production

W. A. Summers, J. L. Steimke, H. R. Colon-Mercado

Savannah River National Laboratory

Steffen Zahn

Air Products and Chemicals, Inc.

September 2013

SRNL-STI-2013-00515

Prepared by Savannah River National Laboratory

Aiken, South Carolina 29808 for the U.S. Department of Energy under contract number DE-AC09-08SR22470. 


\section{DISCLAIMER}

This work was prepared under an agreement with and funded by the U.S. Government. Neither the U.S. Government or its employees, nor any of its contractors, subcontractors or their employees, makes any express or implied:

1. warranty or assumes any legal liability for the accuracy, completeness, or for the use or results of such use of any information, product, or process disclosed; or

2. representation that such use or results of such use would not infringe privately owned rights; or

3. endorsement or recommendation of any specifically identified commercial product, process, or service.

Any views and opinions of authors expressed in this work do not necessarily state or reflect those of the United States Government, or its contractors, or subcontractors.

\section{Printed in the United States of America \\ Prepared for \\ U.S. Department of Energy}




\section{CRADA Final Report for CRADA No. CR-12-006: Operation and Testing of an $\mathrm{SO}_{2}$-depolarized Electrolyzer (SDE) for the Purpose of Hydrogen and Sulfuric Acid Production}

William A. Summers

John L. Steimke

Hector R. Colon-Mercado

September 2013

APPROVED FOR PUBLIC RELEASE; DISTRIBUTION IS UNLIMITED

Prepared for the U.S. Department of Energy under contract number DE-AC09-08SR22470.

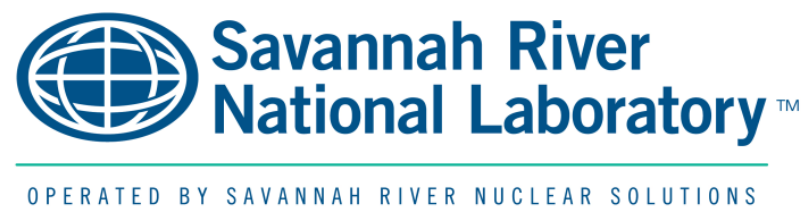




\begin{abstract}
Over the past several years, Savannah River National Laboratory (SRNL) has led a team of collaborators under the Department of Energy's (DOE) nuclear hydrogen production program to develop the Hybrid Sulfur (HyS) Process. HyS is a 2-step water-splitting process consisting of high temperature decomposition of sulfuric acid to generate $\mathrm{SO}_{2}$, followed by the electrolysis of aqueous $\mathrm{SO}_{2}$ to generate hydrogen and sulfuric acid. The latter is fed back into the high temperature reactor. SRNL designed and built an $\mathrm{SO}_{2}$-depolarized electrolyzer (SDE) and a test facility. Over 40 SDE's were tested using different catalysts, membranes and other components. SRNL demonstrated that an SDE could be operated continuously for approximately 200 hours under certain conditions without buildup of sulfur at the SDE's cathode, thus solving a key technical problem with SDE technology. Air Products and Chemicals, Inc. (APCI) is a major supplier of hydrogen production systems, and they have proprietary technology that could benefit from the SDE developed by SRNS, or some improved version thereof. However, to demonstrate that SRNL's SDE is a truly viable approach to the electrolyzer design, continuous operation for far greater periods of time than 200 hours must be demonstrated, and the electrolyzer must be scaled up to greater hydrogen production capacities.
\end{abstract}

SRNL and Air Products entered into a Cooperative Research and Development Agreement with the objective of demonstrating the effectiveness of the SDE for hydrogen and sulfuric acid production and to demonstrate long-term continuous operation so as to dramatically increase the confidence in the SDE design for commercial operation. SRNL prepared a detailed technical report documenting previous SDE development, including the current SDE design and operating conditions that led to the 200-hour sulfurfree testing. SRNL refurbished its single cell SDE test facility and qualified the equipment for continuous operation. A new membrane electrode assembly (MEA) was fabricated and installed in the single cell electrolyzer $\left(60 \mathrm{~cm}^{2}\right.$ active cell area). Shakedown testing was conducted, and several modifications were made to the test facility equipment. Seven different MEAs were used during testing. Beginning on May 20, 2013, SRNL was able to test the SDE continuously for 1200 hours, including 1000 hours under power to generate hydrogen at an average rate of 10.8 liters per hour. The SDE was not removed or repaired during the 50-day test and was successfully restarted after each shutdown. The test was intentionally stopped after 1200 hours (1000 hours of hydrogen production) due to funding constraints. Post-test examination of the MEA using Scanning Electron Microscopy (SEM) and Energy Dispersive X-ray Microanalysis (EDAX) showed no elemental sulfur deposits or sulfur layer inside the cell, thus successfully achieving the test goals. The results demonstrated that the SDE could be operated for extended periods without major performance degradation or the buildup of sulfur inside the MEA.

Air Products conducted an assessment of the economic viability of the SDE based on the "as tested" design. The results indicated that the SDE faces significant economic obstacles in its current state. Further development and scale-up are necessary before the SDE is ready for commercialization. 


\section{TABLE OF CONTENTS}

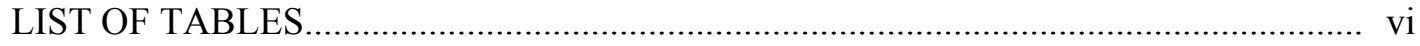

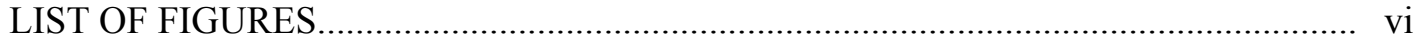

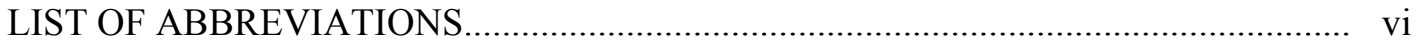

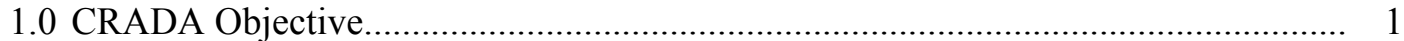

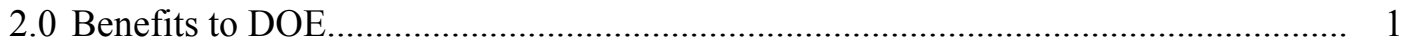

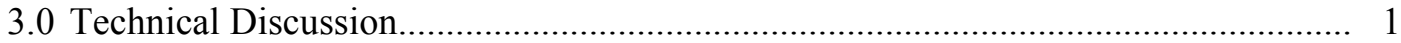

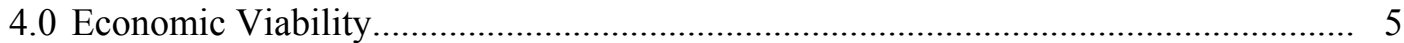

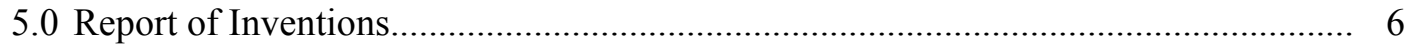

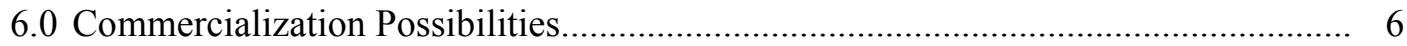

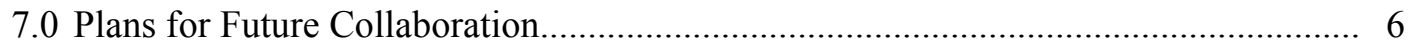

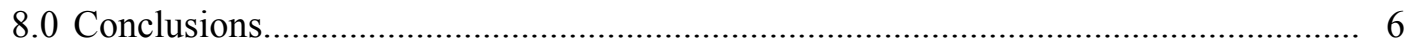




\section{LIST OF TABLES}

\section{LIST OF FIGURES}

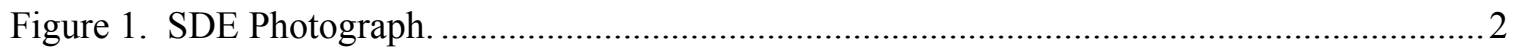

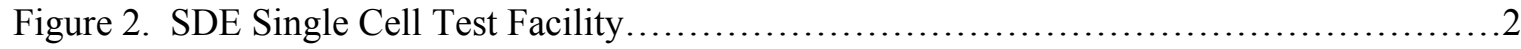

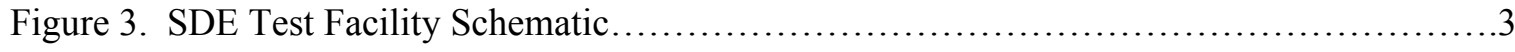

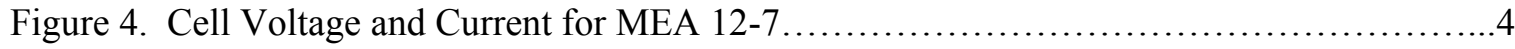

Figure 5. SEM Photograph of MEA 12-7 showing dimensions .............................

\section{LIST OF ABBREVIATIONS}

CRADA Cooperative Research and Development Agreement

DOE Department of Energy

EDAX Dispersive X-ray Microanalysis

HyS Hybrid Sulfur

MEA Membrane Electrode Assembly

PEM Proton Exchange Membrane

$\mathrm{SDE} \quad \mathrm{SO}_{2}$-depolarized Electrolyzer

SEM Scanning Electron Microscopy

SRNL Savannah River National Laboratory 


\subsection{CRADA Objective}

The objectives of this CRADA were to demonstrate the effectiveness of the $\mathrm{SO}_{2}$-depolarized Electrolyzer (SDE) for hydrogen and sulfuric acid production and to demonstrate long-term continuous operation so as to dramatically increase the confidence in the SDE design for commercial operation. By continuous operation is meant operation without encountering problems caused by physical-chemical processes such as buildup of an elemental sulfur layer at the cathode that clogs pores of the membrane or chemical degradation of the membrane, etc. Disruptions of operation due to power outages, or failure of associated equipment such as pumps or computers, and the like, were not considered a failure to obtain continuous operation, so long as operation could be re-established at conditions similar to the operation before the disruption occurred (i.e., similar voltage, pressure drop and hydrogen output rate) without requiring removal or repair of the cell itself.

The CRADA consisted of two main tasks:

1. Preparation of a detailed report providing the current SDE design and operating conditions that allowed SRNL to successfully operate the SDE for 200 hours without sulfur buildup at the cathode;

2. Demonstration of SDE performance over a continuous period of operation in excess of 1000 hours followed by disassembly of the SDE and examination and analysis of the MEA to determine the existence, or lack thereof, of conditions which would be indicative of a shorter than expected lifetime, such as buildup of elemental sulfur at the cathode.

The overall accomplishments during the CRADA are described in this report.

\subsection{Benefits to DOE}

DOE can leverage the work performed under this CRADA in support of its on-going research and development efforts related to hydrogen production using solar and nuclear heat sources. The demonstration of long-term SDE operation without limiting physical or chemical processes provides much greater confidence in the technology's reliability and suitability for use in the Hybrid Sulfur thermochemical hydrogen production process. DOE also receives valuable information on the commercial attractiveness of the SDE from Air Products and Chemicals, Inc., one of the world's largest supplier of hydrogen. DOE may also benefit from royalty streams and an enhanced reputation for the development of practical, commercial technology, should the long term objectives of Air Products for commercial deployment of the technology prove successful. Success may also result in new jobs in the U.S., and/or the protection of existing jobs, which would also enhance DOE's reputation.

\subsection{Technical Discussion}

The SDE electrochemically oxidizes sulfur dioxide to form sulfuric acid at the anode [r1] and reduces protons to form hydrogen at the cathode [r2]. The overall electrochemical reaction consists of the production of $\mathrm{H}_{2} \mathrm{SO}_{4}$ and $\mathrm{H}_{2}$ [r3].

$$
\begin{array}{ll}
\mathrm{SO}_{2}+2 \mathrm{H}_{2} \mathrm{O} \rightarrow \mathrm{H}_{2} \mathrm{SO}_{4}+2 \mathrm{H}^{+}+2 \mathrm{e}^{-} & \text {Anode Electrochemical Step } \\
2 \mathrm{H}^{+}+2 \mathrm{e}^{-} \rightarrow \mathrm{H}_{2} & \text { Cathode Electrochemical Step } \\
\mathrm{SO}_{2}+2 \mathrm{H}_{2} \mathrm{O} \rightarrow \mathrm{H}_{2} \mathrm{SO}_{4}+\mathrm{H}_{2} & \text { Overall Electrochemical Step }
\end{array}
$$


SRNL has developed an SDE design which employs a proton-exchange membrane (PEM) as the electrolyte. $\mathrm{SO}_{2}$ dissolved in sulfuric acid is fed to the anode side of the cell, where reaction 1 occurs. Hydrogen is produced on the cathode side of the cell. A versatile single cell SDE with a $60-\mathrm{cm}^{2}$ active cell area is employed for testing. Photographs of the SDE and the test facility are shown in Figures 1 and 2, respectively.

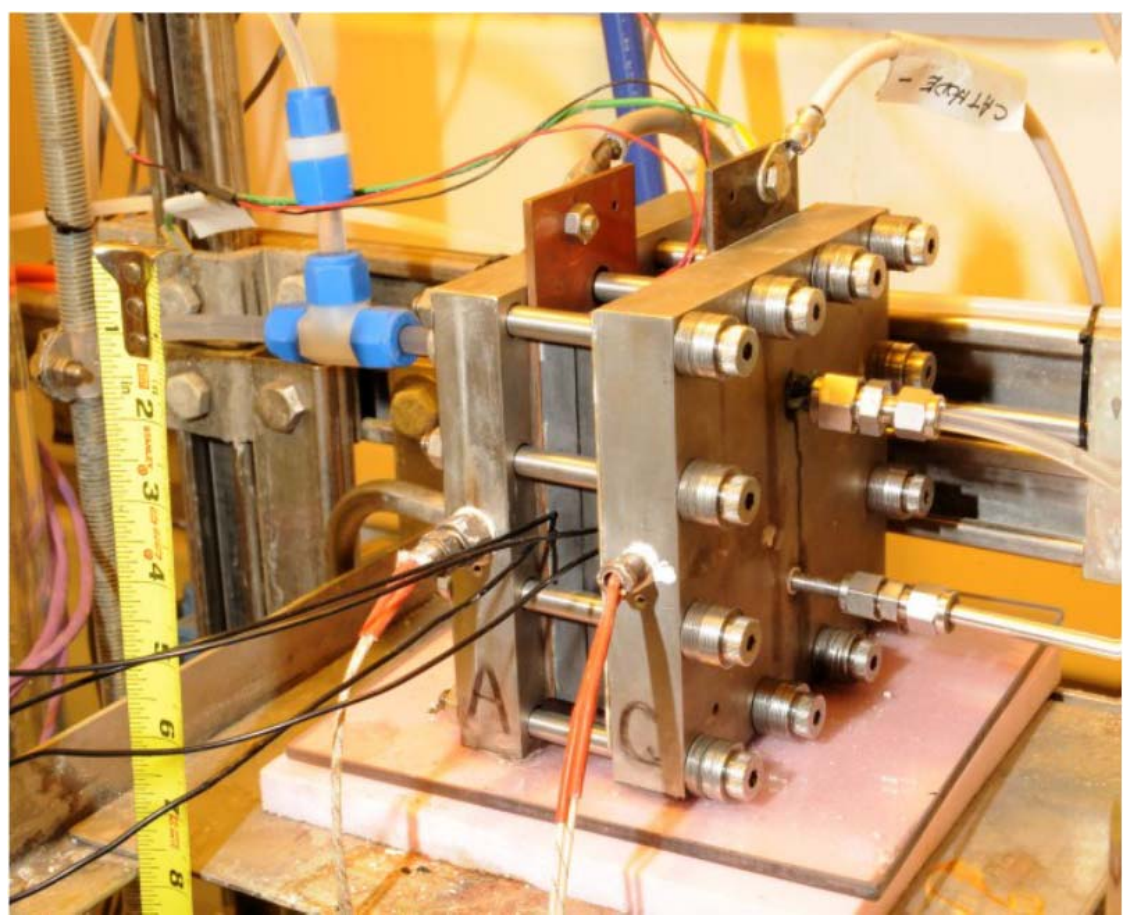

Figure 1. SDE Photograph

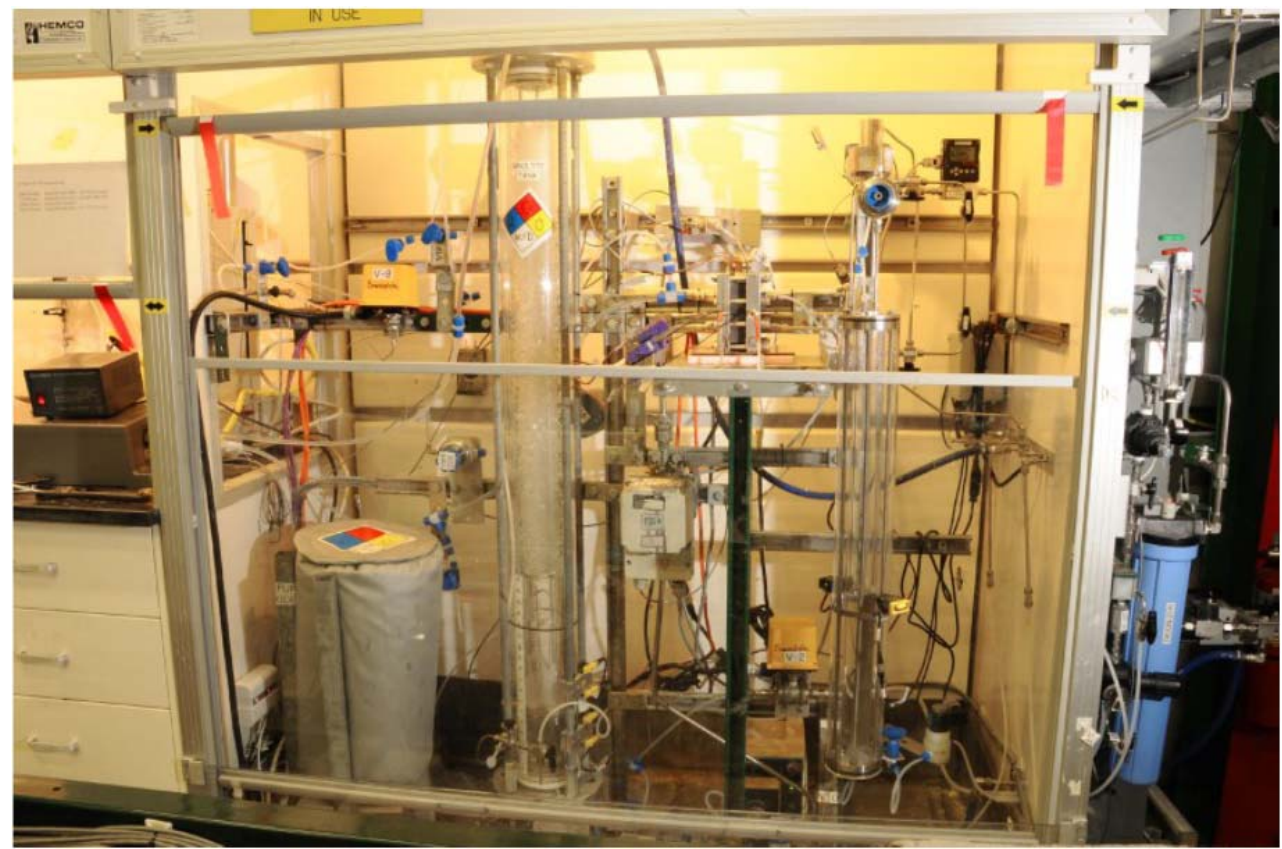

Figure 2. SDE Single Cell Test Facility 
Under the terms of this CRADA, SRNL prepared a technical report documenting previous SDE development, including the current SDE design and operating conditions that resulted in successful SDE operation for periods up to 200 hours without sulfur buildup at the cathode. The Task 1 final report (SRNL-STI-2012-00695) contains the following information:

1. History of development effort

2. Design considerations for the electrolyzer cell and the detailed design

3. Design considerations for the balance of facility and the detailed design

4. Instrumentation and Data Acquisition System

5. Automatic controls and safety circuits

6. General observations of SDE performance

7. Cause of sulfur accumulation problem

8. Solution of sulfur accumulation problem and operational parameters to allow long term operation

9. Representative test data, drawings, and work instructions.

Issuance of the technical report completed Task 1.

Task 2 consisted of refurbishment and restart of the SRNL single cell SDE test facility and the demonstration of long-term SDE continuous operation, followed by post-test examinations. Figure 3 shows a simple schematic of the test facility hardware.

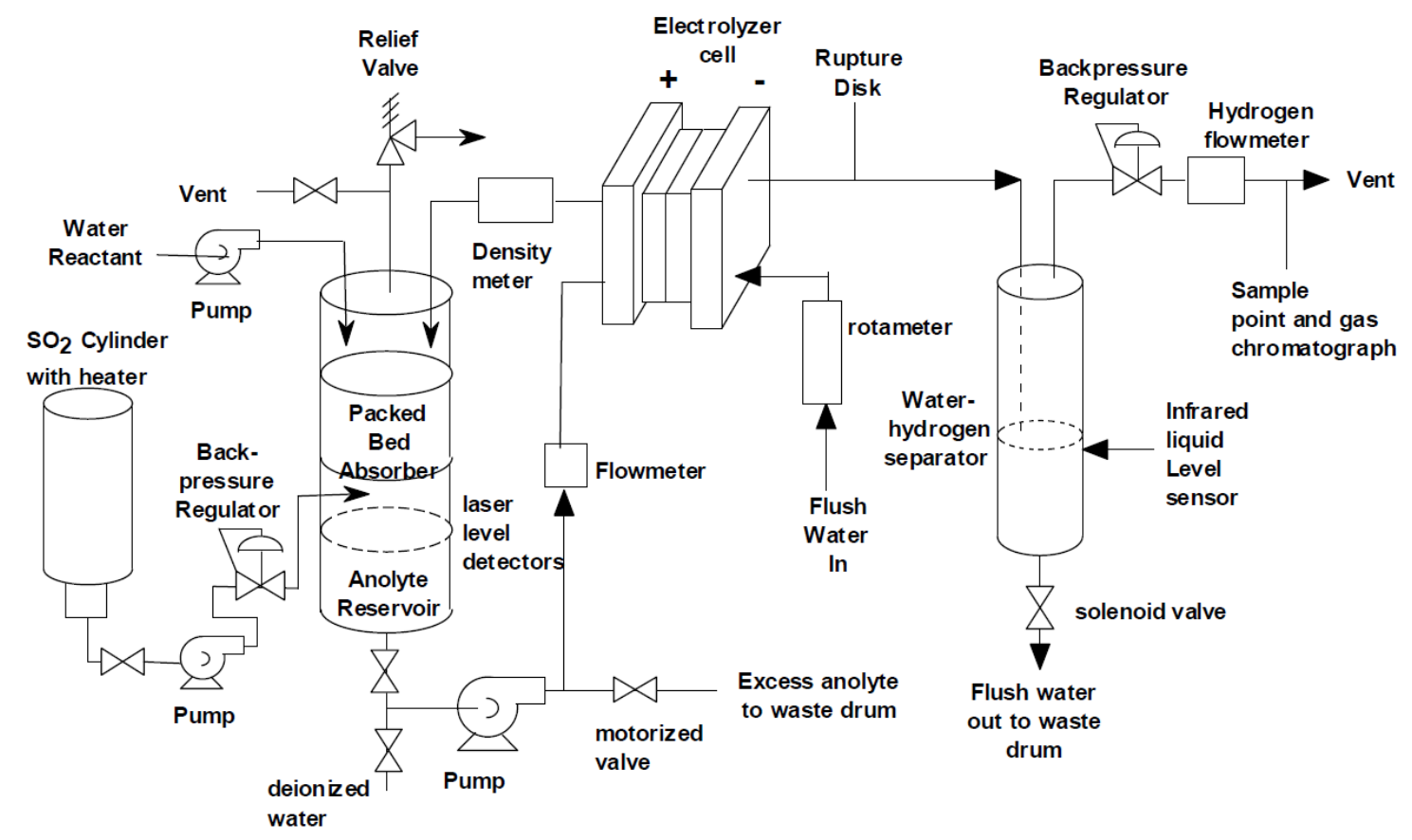

Figure 3. SDE Test Facility Schematic

The heart of the equipment is the electrolyzer cell (SDE), which contains a membrane electrode assembly (MEA). The MEA consists of a Nafion ${ }^{\circledR} 115$ membrane with a thin layer of porous platinized carbon on both sides forming an anode and cathode. The rest of the cell provides mechanical strength, flow passages for anolyte and hydrogen, and electrical contact between the power supply, anode and cathode. 
After the test facility was refurbished and readied for testing, a new MEA was fabricated and installed in the single cell electrolyzer $\left(60 \mathrm{~cm}^{2}\right.$ active cell area). Shakedown testing required more time and effort than originally planned due to several facility equipment failures, power outages and computer upsets. This required replacing the MEA several times and restarting testing. Beginning on May 20, 2013, SRNL was able to test the seventh MEA continuously for 1200 hours, including 1000 hours under power to generate hydrogen at an average rate of 10.8 liters per hour. The SDE was not removed or repaired during the 50-day test and was successfully restarted after each shutdown. The test was intentionally stopped after 1200 hours (1000 hours of hydrogen production) due to funding constraints on July 9, 2013.

Figure 4 shows the cell voltage and current for MEA 12.7. Total time that MEA 12.7 was installed in the test facility was 1200 hours. Periods when the test was shut down, such as over some weekends, were removed from the plot, resulting in 1000 hours during which the SDE was producing hydrogen. Voltage was measured at the carbon plates inside the cell, so it does not include voltage losses in the cables. Voltage was maintained at an average 0.85 volt throughout the test.

Cell Voltage and Current for MEA 12-7

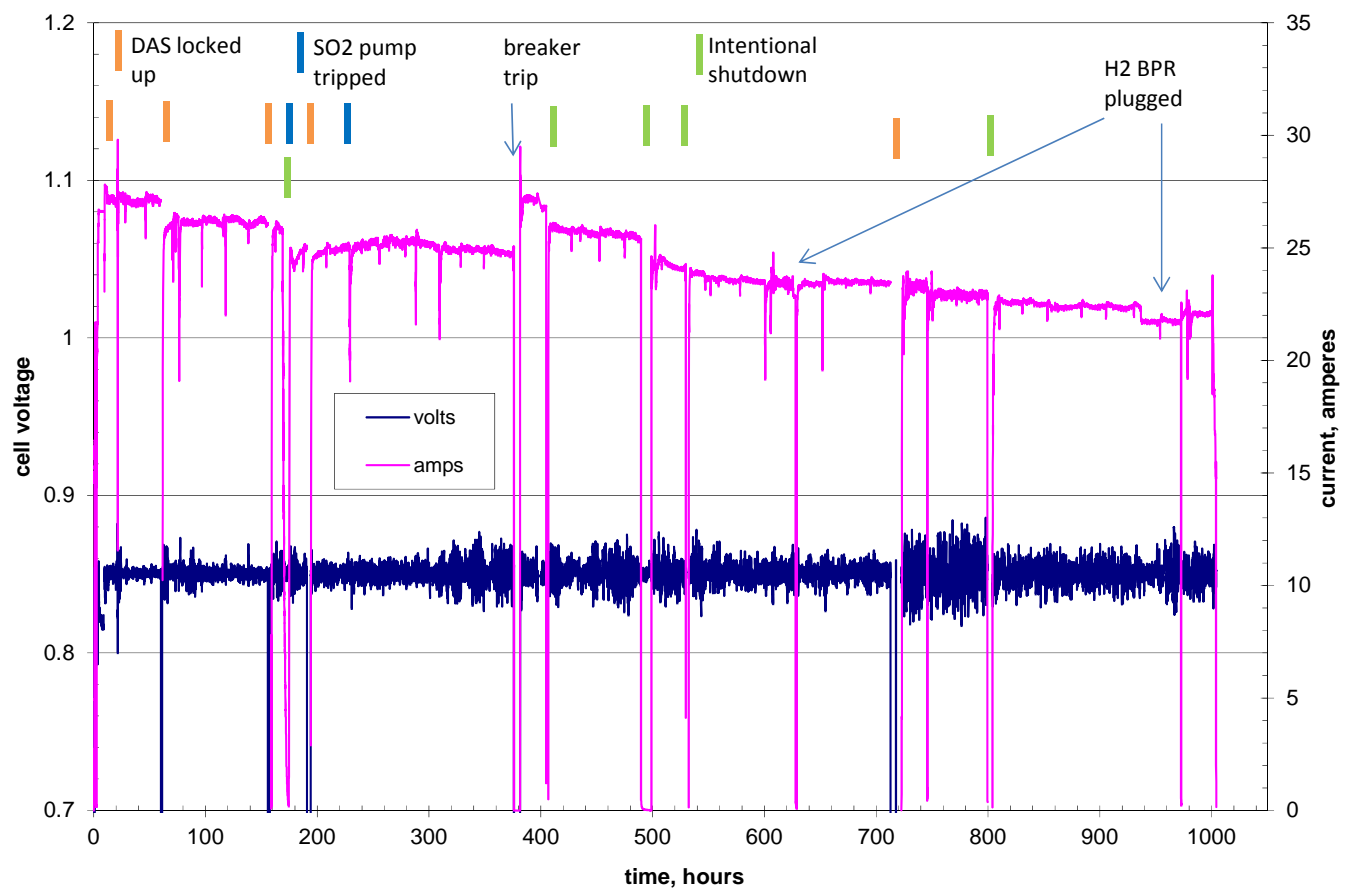

Figure 4. Cell Voltage and Current for MEA 12-7 
At the completion of the test, the cell was removed from the test facility, inspected, and the MEA was subjected to post-test examination using Scanning Electron Microscopy (SEM) and Energy Dispersive X-ray Microanalysis (EDAX). An SEM photograph of the cross section of the MEA is shown in Figure 5.

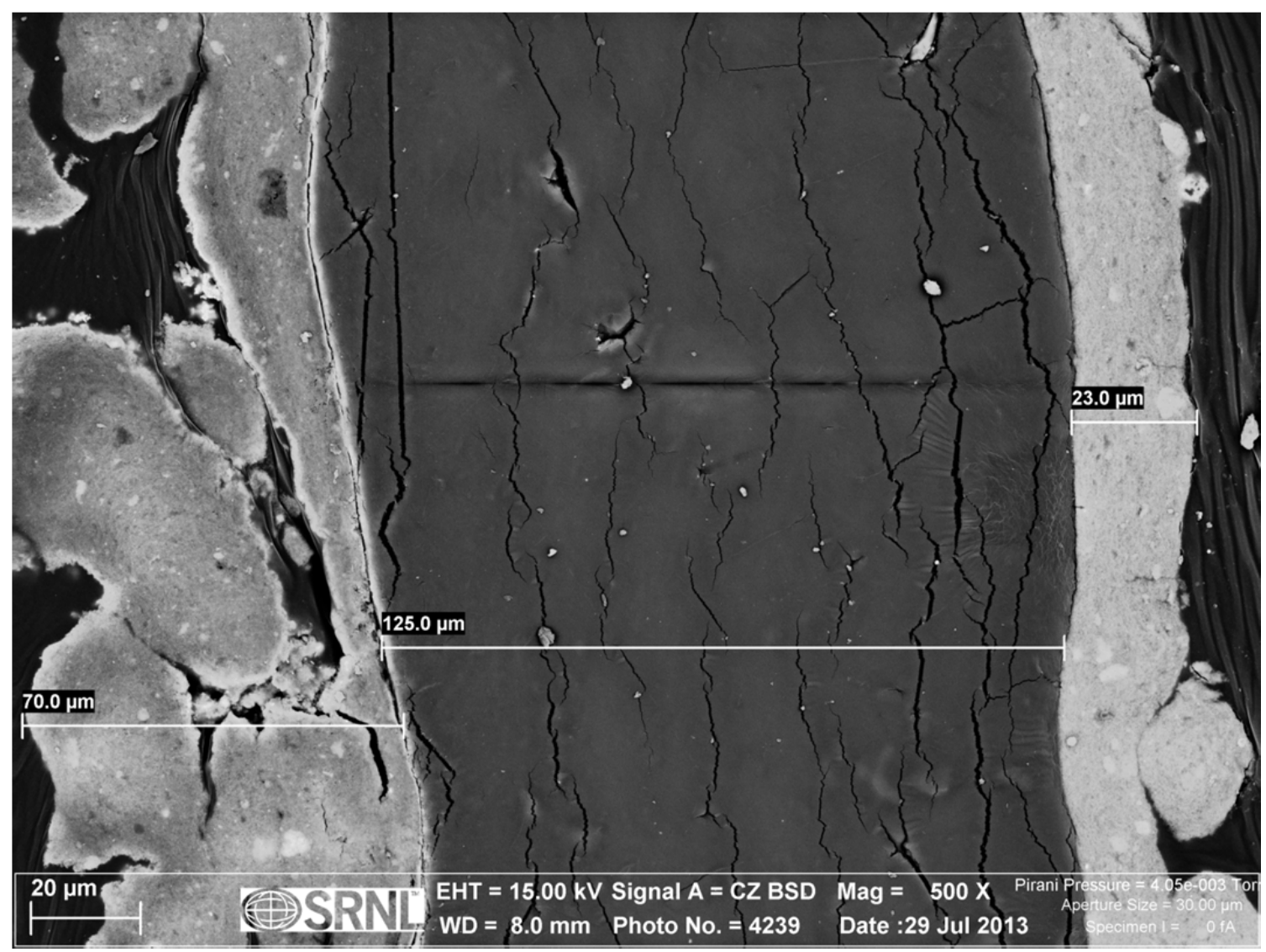

Figure 5. SEM Photograph of MEA 12.7 showing dimensions

The anode is on the left hand side. Nafion 115 is nominally 5 mils or 125 um thick, which agrees with that thickness in the SEM. The anode and cathode are 70 um and 23 um thick respectively. There is no sulfur layer visible in the SEM. During previous SDE testing in 2008, sulfur layers were prominently visible in SEM analysis for cells operated in the "sulfur-forming" region. The EDAX results verified the absence of sulfur-rich regions that would indicate the buildup of a sulfur layer.

The absence of elemental sulfur deposits or a sulfur layer inside the cell after continuous longterm endurance testing demonstrates that a solution to one of the most troubling aspects of SDE operation has been achieved. This was the primary goal of the test program. A final technical report (SRNL-TR-2013-00170) was prepared documenting the Task 2 endurance testing of the SDE. This completed Task 2.

\subsection{Economic Viability}

The economic viability of the SDE as a potential technology option for hydrogen production was estimated based on its current performance. The capital expenditure for replicating the SDE test facility (Figure 3 ) was assessed by Air Products (Table 1). 
SRNL-STI-2013-00515

\begin{tabular}{|c|c|c|c|c|c|c|c|c|c|c|c|}
\hline \multicolumn{12}{|c|}{ Overall Project Budget } \\
\hline & $\begin{array}{l}\text { Labor } \\
\text { Hours }\end{array}$ & $\begin{array}{l}\text { Labor } \\
\text { Budget }\end{array}$ & $\begin{array}{c}\text { Materials } \\
\text { Budget }\end{array}$ & $\begin{array}{l}\text { Labor } \\
\text { Budget w/ } \\
\text { Reserve }\end{array}$ & $\begin{array}{l}\text { Materials } \\
\text { Budget w/ } \\
\text { Reserve }\end{array}$ & $\begin{array}{l}\text { Labor } \\
\text { Reserve } \\
\text { Ammount }\end{array}$ & $\begin{array}{l}\text { Materials } \\
\text { Reserve } \\
\text { Ammount }\end{array}$ & $\begin{array}{l}\text { Average } \\
\text { Reserve }\end{array}$ & $\begin{array}{l}\text { Overall } \\
\text { Budget }\end{array}$ & $\begin{array}{l}\text { Budget w/ } \\
\text { Reserve }\end{array}$ & $\begin{array}{c}\text { Overall } \\
\text { Reserve } \\
\text { Ammount }\end{array}$ \\
\hline $\begin{array}{c}\text { Automation } \\
\text { Calibration }\end{array}$ & 195 & 22,425 & 31,040 & 25,789 & 32,921 & 3,364 & 1,881 & $10 \%$ & 53,465 & 58,710 & 5,245 \\
\hline Electrical & 320 & 28,160 & 4,800 & 32,384 & 5,520 & 4,224 & 720 & $15 \%$ & 32,960 & 37,904 & 4,944 \\
\hline $\begin{array}{r}\text { Engineering } \\
\text { Glass }\end{array}$ & 343 & 39,445 & 131,078 & 45,937 & 149,310 & 6,492 & 18,232 & $14 \%$ & 170,523 & 195,246 & 24,723 \\
\hline Life Safety & 80 & 7,040 & 14,578 & 8,800 & 18,223 & 1,760 & 3,645 & $25 \%$ & 21,618 & 27,023 & 5,405 \\
\hline Machining & 454 & 39,952 & 12,500 & 47,652 & 14,765 & 7,700 & 2,265 & $19 \%$ & 52,452 & 62,417 & 9,965 \\
\hline $\begin{array}{r}\text { Mechanical } \\
\text { Proj Tech } \\
\text { Welding } \\
\text { Instrumentation }\end{array}$ & 406 & 35,728 & 4,000 & 42,636 & 4,750 & 6,908 & 750 & $19 \%$ & 39,728 & 47,386 & 7,658 \\
\hline & 1798 & $\$ 172,750$ & $\$ 197,996$ & $\$ 203,198$ & $\$ 225,488$ & $\$ 30,448$ & $\$ 27,492$ & $16 \%$ & $\$ 370,746$ & $\$ 428,686$ & $\$ 57,940$ \\
\hline
\end{tabular}

Table 1. SDE Cost Estimate

It was assumed that the SDE is capable of generating up to $40 \mathrm{~L} / \mathrm{hr}$ of hydrogen. Air Products is looking for hydrogen generators capable of producing 1 MM SCFD Hydrogen. Estimating the potential cost of the SDE for a 1 MM SCFD Hydrogen output from its current scale was not trivial. The materials budget $(\$ 197,996)$ was analyzed in detail. Three line items appeared to potentially govern the materials budget; the Anolyte Tank, the Anolyte Pump, the Electrolyzer. The anolyte pump and anolyte tank sizes required for a 1 MM SCFD Hydrogen generator were determined and budgetary proposals requested. While the anolyte pump was quoted at a modest $\$ 120,000$, the budget quote for the tantalum lined anolyte tank was in the $\$ 15$ million to $\$ 20$ million range.

The demonstrated performance of the SDE displayed a loss in hydrogen production within 1,000 hours which may require monthly replacement of the MEA. At the current performance level, about $160 \mathrm{~m}^{2}$ of MEA are needed to generate 1 MM SCFD hydrogen. The cost for a monthly MEA replacement, based on materials only, appeared to contribute $\$ 2-\$ 3$ to every kilogram of hydrogen produced.

The SDE faces significant economic obstacles in its current state. Further investigations into commercial-scale acid handling equipment designs could potentially lower the cost of the SDE. Improvements in cell performance as well as SO2 delivery are needed in order to consider this hydrogen generation technology for commercial applications.

\subsection{Report of Inventions}

No new inventions were reported.

\subsection{Commercialization Possibilities}

Opportunities for commercialization of the technology demonstrated under this program are viewed as existing within the private sector and government agencies. Additional research and development is required to improve the cell performance and to scale-up to commercial sizes.

\subsection{Plans for Future Collaboration}

No current plans.

\subsection{Conclusions}

The work under CRADA CR-12-006 with Air Products and Chemicals, Inc. has been completed. In addition to this CRADA final report, two major technical reports were prepared to document the results. The major goal of the project was to demonstrate long-term operation of the SDE without limitations caused by sulfur formation or other life-shortening phenomena. This was successfully achieved, indicating that the SDE could be a viable alternative for hydrogen 
production using the Hybrid Sulfur thermochemical cycle or related alternatives. An assessment of the economic viability of the SDE based on the "as tested" design indicated that the SDE faces significant economic obstacles in its current state. Further development and scale-up are necessary before the SDE is ready for commercialization. 